\title{
Exercise and pelvic girdle pain during pregnancy. Are there any associations?
}

\author{
Lene Annette Hagen Haakstad $^{{ }^{*}}$, Elisabeth Wiken Telenius ${ }^{2}$, Kari Bø ${ }^{1}$ \\ ${ }^{1}$ Department of Sports Medicine, Norwegian School of Sports Sciences, Oslo, Norway \\ ${ }^{2}$ Faculty of Health Sciences, Oslo and Akershus University College of Applied Sciences, Oslo and Kjeller, Norway \\ Email: 1 lahaakstad@nih.no
}

Received 12 June 2013; revised 14 July 2013; accepted 25 July 2013

Copyright (C) 2013 Lene Annette Hagen Haakstad et al. This is an open access article distributed under the Creative Commons Attribution License, which permits unrestricted use, distribution, and reproduction in any medium, provided the original work is properly cited.

\begin{abstract}
Background: To date, there is scant knowledge and inconsistent results about physical activity, exercise and job strain in relation to pelvic girdle pain (PGP). Hence, the aims of the present study were: 1$)$ determine prevalence of PGP and severe PGP during pregnancy and 2) compare background and lifestyle factors in addition to total physical activity level (at work, commuting, housework and recreational exercise) in those who experienced PGP and those who did not in pregnancy. Methods: Healthy pregnant women $(n=467)$ were allocated to the study from Oslo University Hospital, Norway. The participants filled in a validated self-administered questionnaire, Physical-Activity-Pregnancy-Questionnaire (PAPQ) in gestation-week 32 - 36. The questionnaire contained 53 questions with nine specific questions addressing PGP. The key question on PGP was asked cross-sectionally and also posed retrospectively for pre-pregnancy, $1^{\text {st }}$ and $2^{\text {nd }}$ trimester (During this pregnancy, did you experience any PGP?) ("Yes versus No"). Results: More than half of the women $(57.5 \%)$ reported to suffer from PGP, with $18.4 \%$ reporting severe PGP. Compared the no-PGP group, women with PGP were significantly more likely to be sick-listed, multiparous, they perceived their job to be physically demanding, as well as had physically demanding household chores, including childcare. In addition, they were more prone to have experienced PGP in previous pregnancies and suffered from urinary incontinence (UI) in the current pregnancy. Most women with severe PGP reported to be sedentary in the $3^{\text {rd }}$ trimester; however they performed more strengthening exercises at home than the women without PGP. Severe PGP also showed an association with standing/walk-
\end{abstract}

"Corresponding author. ing $\mathbf{2 5 0} \%$ at work. Conclusion: Women who exercised regularly in the $3^{\text {rd }}$ trimester were less likely to report PGP, while job strain was associated with higher prevalence of PGP. There is a need for a prospective study with larger sample size to further evaluate if exercise has any causal association with PGP.

Keywords: Exercise; Pelvic Girdle Pain; Pregnancy; Work Strain

\section{INTRODUCTION}

Recommendations for exercise during pregnancy suggest that, in absence of medical and obstetric complications, pregnant women should aim to perform at least $30 \mathrm{~min}$ utes or more of moderate intensity physical activity daily, and/or exercise 3 - 5 times weekly for a minimum of 15 30 minutes [1,2]. However, being pregnant is followed by increased body mass, as well as several changes in the musculoskeletal system, with possible subsequent pregnancy complaints [3]. To date, pregnant women constitute one third of all sick-leave for women aged between $20-39$, and by 32 weeks of gestation, $63 \%$ of Norwegian women are on sick-leave [4]. According to Dørheim [4], pelvic girdle pain (PGP) accounts for most of the sick leave in pregnancy in Northern European countries. In Sweden, the average sick-leave due to pelvic girdle pain during pregnancy is 7 weeks and it is reported that prevalence is $49 \%$ [5]. Thus, this has large socioeconomic implications, as well as significant impact on physical and psychological quality of life for the women and their families.

The most common hypothesis for the development of this condition is a combination of hormonal and biomechanical factors [3], and although the aetiology, risk factors, prognosis and treatments for this condition have been investigated, many questions are still left unan- 
swered. A main challenge has been the lack of defined diagnostic criteria, terminology and classification systems, making it difficult to compare results from different studies [3,6]. Vleeming et al. [3] have described PGP aspain that usually arises in relation to pregnancy, trauma, osteo-arthritis and arthritis, with an increase in pain intensity as pregnancy advances. Pain is experienced between the posterior iliac crest and the gluteal fold, particularly in the vicinity of the sacroiliac joints (SIJ). Hence, the endurance capacity for standing, walking and sitting is diminished, and there might be a reduction in daily activity and exercise levels.

Strategies to manage PGP and disability are varied and vague due to lack of comprehensive knowledge [7]. To date common management options are patient education, use of pelvic belts, acupuncture, aquatic and stabilization exercise programs [3]. Most intervention studies have applied specific stabilization training as treatment of postpartum [8,9] and pregnancy related PGP [10]. To our knowledge only two studies has evaluated the effect of leisure time exercises on PGP $[11,12]$. Also in observational studies, few researchers have investigated the association between daily activity, exercise or work strain in relation to PGP [13-15]. Mogren [14] found that a high number of years of regular leisure physical activity pre-pregnancy may decrease the risk of LBP and PGP during pregnancy. However, no data on exercise during pregnancy was presented. Gjestland et al. [13] reported that women who exercised $>3$ times weekly were less likely to report PGP, but did not report on total physical activity level (at work, commuting, housework and recreational exercise). According to "European guidelines for diagnosis and treatment of PGP", there is conflicting evidence regarding the association between PGP and heavy workload or job strain [3]. Hence, the aims of the present study were: 1) determine prevalence of PGP and severe PGP during pregnancy and 2) compare background, lifestyle factors and total physical activity level (at work, commuting, housework and recreational exercise) in those who experienced PGP and those who did not.

\section{MATERIALS AND METHODS}

This present research project was designed as a crosssectional study with a self-administered questionnaire, Physical-Activity-Pregnancy-Questionnaire (PAPQ), filled in by all participants in mean gestation-week 36.4 (SD 1.7). The questions on total physical activity level within the four arenas; commuting, occupation, housework and childcare activities, as well as sport/exercise questions have been validated with data from a motion monitor (ActiReg ${ }^{\circledR}$, PreMed AS, Oslo, Norway), with acceptable results [16].
Study recruitment took place between 2002 and 2005, and healthy pregnant women were enrolled from the application form for birth at Rikshospitalet University Hospital, Oslo. This is the secondary analysis of cohort data collected as a part of a prospective study of determinants of macrosomic infants in Norway (STORK). Results from the main study have been published separately [17, 18]. General inclusion criteria were: 1) enrolment to the project before week 14 of gestation; 2) expecting a singleton fetus; 3) answer the physical activity questionnaire in the third trimester and 4) being of Scandinavian origin and understand the Norwegian language. Exclusion criterion was: pre-gestational diabetes due to the primary aim of the main study. Of the 2145 women who were invited to participate in the parent STORK study, 678 accepted the invitation. However, 90 withdrew before inclusion. Fourteen women were excluded after routine ultrasound at gestation week $17-18$, due to congenital disorders $(\mathrm{n}=8)$ and twin births $(\mathrm{n}=6)$. Further exclusions were two stillbirths, eleven relocations and births at another hospital, and eight participants chose to withdraw. Hence, of the 553 women enrolled in the STORK study, $467(84.4 \%)$ received our supplementary self-administered questionnaire. The STORK project followed the Helsinki declaration, and all the women gave written informed consent to participate. The Regional Committee for Medical and Health Research Ethics, Southern Norway, Oslo and the Norwegian Social Sciences Data Services approved the project.

\subsection{Assessment Procedures and Outcome Measures}

\subsubsection{Total Physical Activity Level}

The PAPQ required about $10-15$ minutes to complete and contained 53 questions, including several detailed questions about physical activity level in transportation, household, at work and exercise, with specific emphasize on the two latter. Exercise has been defined as "repetitive, planned and structured bouts of physical activity, conducted over a period of weeks or months, with the intention of improvement or maintenance of "physical fitness" [19]. In the present study, regular exercise was defined as participating in one or more exercise activities of moderate intensity per week with at least 20 minutes duration [20]. The participants were asked how long they had been exercising regularly and their three most preferred activities. In addition they answered questions about frequency (How often do you exercise weekly?), duration (For how long time do you usually exercise? and intensity (On what intensity do you regularly exercise ?). The same questions were asked cross-sectionally (gestation week 32 - 36) and retrospectively (pre-pregnancy, at $1^{\text {st }}$ and $2^{\text {nd }}$ trimester). 
To assess heavy workload or job strain, we included four different questions with the following definitions, as well as identified participants working shift (outside common daytime hours, between 8 am and $5 \mathrm{pm}$ ):

Do you perform your work standing and/or walking? ( $>50 \%$ of the time)

How often do you perform heavy lifts at work? ( $>20$ heavy lift a day)

Do you need to twist or bend to complete your work? $(>50 \%$ of the time)

Would you characterize your job as physically demanding? (Yes or No)

\subsubsection{Background and Health Variables}

Information on background and health variables included: age, education, occupation, parity, height, weight, prepregnancy BMI, maternal weight gain, daily smoking, reports of being sick-listed and pregnancy complaints. Assessments of the number of women experiencing PGP were obtained as part of the questions concerning pregnancy complaints and included a yes or no response to one question: "During this pregnancy do you experience $P G P$ ?" If the participants answered yes to this question, measure of the disability or severity of the condition was investigated: "Do you have problems walking to the extent of using crutches?" The response options were: "Not at all, Seldom, Sometimes or Most of the day". Severe PGP was defined as using crutches "Sometimes or Most of the day". The two questions on PGP were asked crosssectionally and also posed retrospectively for pre-pregnancy, $1^{\text {st }}$ and $2^{\text {nd }}$ trimester. Further, we included two questions to obtain information about foregoing PGP, as this may be considered possible confounders when examining the association between total physical activity level and PGP at present [3]. "During previous pregnancies, did you experience any PGP?" ("Yes versus No"). A yes response was followed by a final question investigating the length/duration of the pain period postpartum: "When did the pain in the pelvic area stop?" The response options were: "Less than 6 weeks after delivery, 6 - 20 weeks after delivery, 5 - 10 months after delivery or I was still in pain when conception".

\subsection{Statistical Analysis}

All statistical analyses were conducted with SPSS Statistical Software version 18.0 for Windows. Data are presented as numbers with percentages or means with standard deviation (SD). Some of the participants did not answer every question, and therefore individual questions may have varying response rates. $\mathrm{X}^{2}$-test was used to compare categorical data and Student's t-test was applied for continuous data. In all analysis, the level of statistical significance was set at $p<0.05$. To assess the relative importance of physical activity/exercise, as well as other lifestyle factors, multivariate odds ratios (ORs) with $95 \%$ confidence intervals (CIs) were estimated using binary logistic regression analysis. In total, 11 relevant variables (multiparity, previous $P G P$, exercise, stand/walk at work, sick-listed, work shift, weight gain, urinary incontinence, demanding work at home, pre-preg $B M I$, pre-preg $B M I \geq 25$ ) with univariate p-values $<0.05$ were entered by a forward variable selection process. Probability for exclusion was chosen as 0.05 .

\section{RESULTS}

In total 467 (84.5\%) women answered the physical activity questionnaire. From these, 464 participants answered the particular questions about PGP in the current pregnancy. One participant was excluded due to an error in the transference of data from questionnaire to the computer file, leaving a final study sample of 463 women (83.7\% of all possible responders).

Table 1 shows background and health variables of the study population, including the proportion reporting PGP and severe PGP. During the current pregnancy, almost $60 \%$ reported to have experienced PGP and approximately $18 \%$ suffered from severe PGP. Previous PGP was experienced by $23 \%$. About $90 \%$ of those who had a

Table 1. Background and health variables of the participants, including data on PGP. The results are presented as means (with standard deviation, SD) or number (and percentage) (n = 463).

\begin{tabular}{ll}
\hline Age (years) & $31.6(4.0)$ \\
College/university degree & $84.6 \%(384)$ \\
Married/cohabiting & $98.9 \%(458)$ \\
Multiparous & $46 \%(213)$ \\
Pre-pregnancy BMI $\left(\mathrm{kg} / \mathrm{m}^{2}\right)$ & $23.6(3.7)$ \\
Pre-pregnancy BMI $\geq 25$ & $28.5 \%(132)$ \\
Weight gain $(\mathrm{kg})$ & $13.8(5.2)$ \\
Daily smokers & $2.6 \%(12)$ \\
Sicklisted in the $3^{\text {rd }}$ trimester & $36.2 \%(163)$ \\
PGP & $57.5 \%(266)$ \\
Severe PGP & $18.4 \%(85)$ \\
PGP during any previous pregnancies & $18.8 \%(88)$ \\
Duration of pain period of PGP postpartum & \\
Within 6 weeks postpartum & $60.9 \%(53)$ \\
7 - 20 weeks postpartum & $20.7 \%(18)$ \\
5 - 10 mounts postpartum & $8 \%(7)$ \\
Chronic pain & $10.3 \%(9)$ \\
Regular exercisers & \\
Pre-pregnancy $^{\text {st }}$ trimester & $81.3 \%(378)$ \\
$2^{\text {nd }}$ trimester & $69.5 \%(322)$ \\
$3^{\text {rd }}$ trimester & $64.0(297)$ \\
\hline
\end{tabular}

*Vigorous leisure time physical activity of minimum 20 minutes on moderate intensity (light breathing and modest sweating) performed at least once a week on regular basis. This definition is similar for all presented tables. 
history of PGP also reported PGPat present. The majority reported recovery from PGP within seven weeks postpartum. However, $18.3 \%$ was still experiencing pain five month postpartum, with $10 \%$ reporting chronic pain. The proportion of women performing regular exercise decreased from pre-pregnancy throughout pregnancy and more than one third of the participants were sick-listed in the $3^{\text {rd }}$ trimester.

Table 2 shows the comparison between women with and without PGP in the current pregnancy. The PGPgroup put on significantly more weight than those without PGP. The group of participants with PGP was also significantly more likely to have a history of PGP and to be multiparous. They were more prone to suffer from urinary incontinence and reported almost twice as often to be sick-listed in the $3^{\text {rd }}$ trimester. In addition, the women with PGP performed more strengthening exercises at home, perceived house work and childcare chores to be demanding and reported to perform their work standing and/or walking $>50 \%$ of the time. As shown in Table $\mathbf{3}$, most of these variables were statistically significant also when comparing the same variables in women with severe PGP to women with no PGP. Fewer women with disability and severe pain from the condition (defined as using crutches sometimes or most of the day) were exercising regularly in the $3^{\text {rd }}$ trimester. In addition, they were less likely to be working shift. In the multivariate logistic regression model (Table 4), three of the significant variables (history of PGP, exercise in the $3^{\text {rd }}$ trimester and home strengthening exercises) were associated with PGP. Only severe PGP was associated with standing and/or walking at work.

\section{DISCUSSION}

In the current study a high number of women reported to suffer from PGP during the present pregnancy $(60 \%)$ and nearly $20 \%$ were classified as having severe PGP. Women with PGP were more likely to have experienced PGP in previous pregnancies, as well as reported more standing/walking activities at work. No significant difference in prevalence of PGP was seen between those reporting to do regular exercise before pregnancy and those not. Exercise in the $3^{\text {rd }}$ trimester was inversely associated PGP.

According to the literature, prevalence numbers of PGP ranges from $20 \%$ to $80 \%$ [21-24]. This wide range may illustrate the use of different definitions and classification systems. The inclusion or exclusion of women with co-existing low back pain and the definitions of PGP have shown to greatly influence the prevalence estimates of PGP [25]. In the present study low back pain

Table 2. Comparison of relevant background and health variables, including job strain, between participants reporting no PGP and PGP. Mean (SD) for continuous variables and n (\%) for categorical variables.

\begin{tabular}{|c|c|c|c|}
\hline & No PGP & PGP & $\mathrm{p}$-value \\
\hline & $\mathrm{N}=197(42.5 \%)$ & $\mathrm{N}=266(57.5 \%)$ & \\
\hline$\overline{\text { Age }}$ & $31.7(3.8)$ & $31.4(4.0)$ & 0.40 \\
\hline College/university education & $84.7 \%(165)$ & $82.3 \%(218)$ & 0.16 \\
\hline Multiparous & $38.1 \%(75)$ & $51.9 \%(138)$ & $<0.01$ \\
\hline Pre-pregnancy BMI $\left(\mathrm{kg} / \mathrm{m}^{2}\right)$ & $23.3(3.5)$ & $23.8(3.8)$ & 0.09 \\
\hline Pre-pregnancy BMI $\geq 25$ & $26.4 \%(52)$ & $30.1 \%(80)$ & 0.38 \\
\hline Weight gain $(\mathrm{kg})$ & $13.1(4.4)$ & $14.3(5.6)$ & 0.01 \\
\hline Sicklisted in the $3^{\text {rd }}$ trimester & $26.2 \%(50)$ & $43.6 \%(113)$ & $<0.01$ \\
\hline PGP during any previous pregnancies & $4.6 \%(8)$ & $37.7 \%(80)$ & $<0.01$ \\
\hline Urinary incontinence & $20.3 \%(40)$ & $28.6 \%(76)$ & 0.04 \\
\hline \multicolumn{4}{|l|}{$\underline{\text { Regular exercisers }}$} \\
\hline Pre-pregnancy & $79.7 \%(156)$ & $82.3 \%(219)$ & 0.50 \\
\hline $1^{\text {st }}$ trimester & $70.4 \%(137)$ & $69.4 \%(184)$ & 0.82 \\
\hline $2^{\text {nd }}$ trimester & $63.8 \%(125)$ & $63.9 \%(170)$ & 0.47 \\
\hline $3^{\text {rd }}$ trimester & $51 \%(100)$ & $43.3(114)$ & 0.10 \\
\hline Home strengthening exercises & $21.9 \%(35)$ & $39.2 \%(87)$ & $<0.01$ \\
\hline Regular exercise $>1$ year & $92.1(139)$ & $88.8(63)$ & 0.23 \\
\hline Working shift & $9.9 \%(19)$ & $6.9 \%(18)$ & 0.24 \\
\hline Stand/ walk at work ( $>50 \%$ of the time) & $45.2 \%(47)$ & $54.8 \%(57)$ & 0.04 \\
\hline Twist/bend at work ( $>50 \%$ of the time) & $15.7 \%(26)$ & $23.1 \%(46)$ & 0.08 \\
\hline$>20$ heavy lift a day at work & $9.6 \%(16)$ & $13.6 \%(27)$ & 0.24 \\
\hline $\begin{array}{l}\text { Perceive their job as physically demanding } \\
\text { Perceive daily housework physically demanding }\end{array}$ & $\begin{array}{l}8.3 \%(14) \\
50 \%(98)\end{array}$ & $\begin{array}{l}14.3 \%(28) \\
59.8 \%(159)\end{array}$ & $\begin{array}{l}0.08 \\
0.04\end{array}$ \\
\hline
\end{tabular}


Table 3. Comparison of relevant background and health variables, including job strain, between participants reporting no PGP and severe PGP. Mean (SD) for continuous variables and n (\%) for categorical variables.

\begin{tabular}{|c|c|c|c|}
\hline & No PGP & Severe PGP & p-value \\
\hline & $\mathrm{N}=197(42.5 \%)$ & $\mathrm{N}=85(18.4 \%)$ & \\
\hline Age & $31.7(3.8)$ & $31.89(4.41)$ & 0.77 \\
\hline College/university education & $84.7 \%(165)$ & $76.2 \%(64)$ & 0.07 \\
\hline Pre-pregnancy BMI (kg/m²) & $23.39(3.5)$ & $24.65(4.35)$ & $<0.01$ \\
\hline $\mathrm{BMI} \geq 25$ & $26.9 \%(52)$ & $38.8 \%(33)$ & 0.05 \\
\hline Weight gain $(\mathrm{kg})$ & $13.1(4.4)$ & $14.2(5.8)$ & 0.09 \\
\hline Sicklisted in the $3^{\text {rd }}$ trimester & $26.2 \%(50)$ & $56 \%(47)$ & $<0.01$ \\
\hline PGP during any previous pregnancies & $4.6 \%(8)$ & $40.3 \%(27)$ & $<0.01$ \\
\hline Urinary incontinence & $20.3 \%(40)$ & $27.1 \%(23)$ & 0.21 \\
\hline Multiparous & $38.1 \%(75)$ & $51.8 \%(44)$ & 0.03 \\
\hline \multicolumn{4}{|l|}{ Regular exercisers } \\
\hline Pre-pregnancy & $79.7 \%(156)$ & $85.9 \%(73)$ & 0.16 \\
\hline $1^{\text {st }}$ trimester & $70.4 \%(137)$ & $71.4 \%(60)$ & 0.86 \\
\hline $2^{\text {nd }}$ trimester & $63.8 \%(125)$ & $57.6 \%(49)$ & 0.33 \\
\hline $3^{\text {rd }}$ trimester & $51 \%(100)$ & $34.1 \%(29)$ & $<0.01$ \\
\hline Home strengthening exercises & $21.9 \%(35)$ & $36.6 \%(26)$ & 0.02 \\
\hline Regular exercise $>1$ year & $92.1(139)$ & $88.8(63)$ & 0.82 \\
\hline Working shift & $9.9 \%(19)$ & $2.4 \%(2)$ & 0.03 \\
\hline Stand/ walk at work ( $>50 \%$ of the time) & $53.3 \%(89)$ & $70.7 \%(41)$ & 0.02 \\
\hline Twist/bend at work ( $>50 \%$ of the time) & $15.7 \%(26)$ & $17.2 \%(10)$ & 0.78 \\
\hline$>20$ heavy lift a day at work & $9.6 \%(16)$ & $15.5 \%(9)$ & 0.22 \\
\hline Perceive their job as physically demanding & $8.3 \%(14)$ & $15.5 \%(9)$ & 0.12 \\
\hline Perceive daily housework physically demanding & $50 \%(98)$ & $61.2 \%(52)$ & 0.09 \\
\hline
\end{tabular}

Table 4. Factors associated with PGP and severe PGP: Logistic Regression analysis. Crude odds ratio (cOR) and adjusted odds ratio (aOR) with $95 \% \mathrm{CI}$.

\begin{tabular}{|c|c|c|c|c|}
\hline \multirow{2}{*}{ Factors } & \multicolumn{2}{|c|}{ Pelvic girdle pain } & \multicolumn{2}{|c|}{ Severe pelvic girdle pain } \\
\hline & a OR with $95 \% \mathrm{CI}$ & p-value & a OR with $95 \% \mathrm{CI}$ & p-value \\
\hline Multiparous & $1.43(0.66-3.11)$ & 0.37 & $1.22(0.37-4.05)$ & 0.75 \\
\hline Previous PGP & $5.09(1.65-15.75)$ & $<0.01$ & $3.63(0.78-16.93)$ & 0.10 \\
\hline Home strengthening exercise & $3.38(1.6-7.13)$ & $<0.01$ & $2.42(0.82-7.14)$ & 0.11 \\
\hline Stand/walk at work & $1.83(0.90-3.71)$ & 0.09 & $3.87(1.23-12.174)$ & 0.02 \\
\hline Sicklisted in the $3^{\text {rd }}$ trimester & $1.07(0.48-2.34)$ & 0.88 & $1.77(0.58-5.41)$ & 0.32 \\
\hline Exercise in the $3^{\text {rd }}$ trimester & $0.62(0.42-0.9)$ & $<0.01$ & $0.61(0.29-1.27)$ & 0.19 \\
\hline Weight gain $(\mathrm{kg})$ & $1.02(0.95-1.1)$ & 0.53 & & \\
\hline Urinary incontinence & $1.02(0.45-2.29)$ & 0.97 & & \\
\hline Demanding work at home & $1.56(0.77-3.16)$ & 0.22 & & \\
\hline Pre-pregnancy BMI (kg/m²) & & & $0.91(0.7-1.18)$ & 0.47 \\
\hline $\mathrm{BMI} \geq 25$ & & & $3.05(0.45-20.63)$ & 0.25 \\
\hline Working shift & & & $0.15(0.01-2.46)$ & 0.18 \\
\hline
\end{tabular}

and PGP were separated with different questions, in accordance with results from $\mathrm{B} \varnothing$ and Backe-Hansen [22], showing that questionnaires are able to distinguish between these two conditions.

The design of the present study limits the interpreta- tion of the results. Cross sectional designs can tell about associations between variables, however cannot advice on cause and effect. In the current study one may suggest that the only causative variable on PGP would be exercise before pregnancy. The results show that the women 
who were exercising prior to pregnancy were exposed to PGP to the same extent as those who were sedentary. This indicates that it is most likely that PGP influences exercise habits and not the other way around, which are supported by the fact that women with severe PGP were significantly less active during the $3^{\text {rd }}$ trimester than the women with no PGP. It is acknowledged that PGP in many cases leads to disabling pain and interferes with ADL activities and locomotion [24], and it is not hard to foresee the intrusion of these symptoms on exercise. On the other hand, it is interesting to notice that there was a strong association between suffering from PGP and doing home strengthening exercises. A possible reason for this is that women with PGP are likely to have been treated by a physiotherapist who may have given them home exercises to manage or treat the pain [22]. There was no association between exercising in $1^{\text {st }}$ and $2^{\text {nd }}$ trimester and PGP. This is in accordance with the results of Eggen et al. [11].

Mogren [14] investigated regular leisure time physical activity prior to pregnancy, occupation and treatment in women with a combination of low back and PGP during pregnancy. In contrast to the results of the current study, Mogren [14] found that a higher number of years with regular physical activity decreased the risk of PGP. Bø and Backe-Hansen [22] demonstrated that a group of elite athletes suffered from PGP to the same extent as their age-matched control group. These two studies may indicate that moderate exercise may be beneficial, but that the advantage is lost if the training is too frequent or intensive. There is no evidence that mode of exercise makes any difference. Some researches suggest that PGP is associated with previous back pain/pelvic pain and strenuous work, which may imply that it comes from precious tissue damage $[3,6]$. Another proposal is that loss of stability may be an important contributor to PGP [26]. In both of these instances, the thought of a physiccally strong and fit body being less vulnerable to this condition is not unlikely. Further studies should be designed to explore this association in more detail.

An association was demonstrated between significant amount of time standing/walking at work and reporting severe PGP. Endresen [27] found that working with the body bent forward was significantly associated with PGP. Contrary to their results, Juhl et al. [15] found that working posture was not associated with a higher risk of PGP. The discrepancy in study findings may be in part be explained by differences in assessment methods and questions asked. In the current study, only those reported to perform their work standing and/or walking $>50 \%$ of the time were defined as having a standing posture at work.

PGP may be considered a "normal" condition of pregnancy, and natural recovery shortly after delivery has been found in some studies [28]. However, in certain cases, the pain will not diminish and the condition develops into a chronic disabling condition, with great influence on everyday life, including work status [29,30]. Albert et al. [24] found that 8.5\% of women still reported PGP at least 2 year after childbirth, which is comparable with findings in the present study $(10.3 \%)$. Hence, it is important to diagnose and give treatment before PGP becomes chronic.

Some have found that significantly more women who suffered from PGP had no professional education [31]. Our results demonstrate a borderline significant association between education and severe PGP. However, it should be kept in mind that almost $85 \%$ of the participants in the present study had a college or university degree. Higher education may indicate less physically demanding jobs with respect to standing/walking at work.

Although the response rate of the women receiving the additional questionnaire concerning total physical activity and PGP $(83.7 \%)$ can be considered high, the response rate of the parent study, the STORK project, was low (23\%). A low response rate may cause selection bias and reduce the external validity of the study. Nevertheless, a strength of our study was that we had comparison data with non-participants giving birth at the same hospital. Mean maternal age, education, marital status, parity, pregnancy weight gain, gestational age at delivery and birth weight were similar between participating and non-participating women. When compared to the general pregnant population giving birth at Ullevål, another major hospital in Oslo, the STORK-women included more non-smokers, but were otherwise similar [17]. In addition, the participants of our study did not know that the questionnaire contained questions on exercise and we are therefore confident that these questions were not the reason for non-response. Hence, the survey population maybe considered to be representative for an urban Norwegian population of Scandinavian origin $[17,18]$. It can also be considered a strength of the present study that a well-qualified midwife was available for consultation when handing in the questionnaire as this may have avoided misinterpretations of the questions.

It may have been a limitation to the study that pregestational diabetes was an exclusion criterion as it could have influenced the recruitment of women with PGP due to a possible relation between PGP and high BMI before pregnancy, weight gain during pregnancy and pre-gestational diabetes. Diabetes is associated with inactivity, obesity and low educational level [32,33]. Another limitation is that retrospective questions are open for recall bias. The effect of social desirability and social approval may influence the participants' answers [34]. Women who reported use of crutches due to PGP were categorized as having severe PGP because one would expect these women to have worse pain than the other women. 
This has been a requisite for free physiotherapy for PGP in Norway. However, due to different clinical practice among physical therapists and general practitioners some women are recommended to use crutches early to prevent increasing pain. More detailed questions including use of body charts and a possibility for the participant to give more information about the location, nature and extent of pain, may have made it easier to correctly classify the women into the two groups (PGP/severe PGP) and women with no PGP. However, Bø and Backe-Hansen [12] have previously validated the questions on PGP with body chart and reported a high agreement in classification.

\section{CONCLUSION}

The present study did not reveal any association between pre-pregnancy exercise history or exercise performed in the $1^{\text {st }}$ or $2^{\text {nd }}$ trimester and PGP. However, associations between PGP and previous PGP and decreased exercise frequency in the $3^{\text {rd }}$ trimester were found. Severe PGP was associated with standing and walking at work. More prospective studies with large sample sizes including questions on total physical activity and exercise level are warranted. There is also a need for randomized controlled trials comparing different exercise regimens to reduce the incidence and severity of PGP during pregnancy.

\section{ACKNOWLEDGEMENTS}

Thanks to the project leaders of STORK: Professors Tore Henriksen and Professor Jens Bollerslev. There are no computing interests or financial disclosure.

\section{REFERENCES}

[1] ACOG (2002) Exercise during pregnancy and the postpartum period. Obstetrics \& Gynecology, 99, 171-173. doi:10.1016/S0029-7844(01)01749-5

[2] Artal, R. and O'Toole, M. (2003) Guidelines of the American College of Obstetricians and Gynecologists for exercise during pregnancy and the postpartum period. British Journal of Sports Medicine, 37, 6-12. doi:10.1136/bjsm.37.1.6

[3] Vleeming, A., Albert, H.B., Ostgaard, H.C., Sturesson, B. and Stuge, B. (2008) European guidelines for the diagnosis and treatment of pelvic girdle pain. European Spine Journal, 17, 794-819. doi:10.1007/s00586-008-0602-4

[4] Dorheim, S.K., Bjorvatn, B. and Eberhard-Gran, M. (2013) Sick leave during pregnancy: A longitudinal study of rates and risk factors in a Norwegian population. BJOG, 120, 521-530. doi:10.1111/1471-0528.12035

[5] Bjorklund, K. and Bergstrom, S. (2000) Is pelvic pain in pregnancy a welfare complaint? Acta Obstetricia et Gynecologica Scandinavica, 79, 24-30. doi:10.1080/j.1600-0412.2000.079001024.x

[6] Wu, W.H., Meijer, O.G., Uegaki, K., Mens, J.M., van Dieen, J.H., Wuisman, P.I. and Ostgaard, H.C. (2004) Pregnancy-related pelvic girdle pain (PPP), I: Terminology, clinical presentation, and prevalence. European Spine Journal, 13, 575-589.

doi:10.1007/s00586-003-0615-y

[7] Vermani, E., Mittal, R. and Weeks, A. (2010) Pelvic girdle pain and low back pain in pregnancy: A review. Pain Practice, 10, 60-71. doi:10.1111/j.1533-2500.2009.00327.x

[8] Gutke, A., Sjodahl, J. and Oberg, B. (2010) Specific muscle stabilizing as home exercises for persistent pelvic girdle pain after pregnancy: A randomized, controlled clinical trial. Journal of Rehabilitation Medicine, 42, 929-935. doi:10.2340/16501977-0615

[9] Stuge, B., Laerum, E., Kirkesola, G. and Vollestad, N. (2004) The efficacy of a treatment program focusing on specific stabilizing exercises for pelvic girdle pain after pregnancy: A randomized controlled trial. Spine, 29, 351359. doi:10.1097/01.BRS.0000090827.16926.1D

[10] Nilsson-Wikmar, L., Holm, K., Oijerstedt, R. and HarmsRingdahl, K. (2005) Effect of three different physical therapy treatments on pain and activity in pregnant women with pelvic girdle pain: A randomized clinical trial with 3, 6, and 12 months follow-up postpartum. Spine, 30, 850-856. doi:10.1097/01.brs.0000158870.68159.d9

[11] Eggen, M.H., Stuge, B., Mowinckel, P., Jensen, K.S. and Hagen, K.B. (2012) Can supervised group exercises including ergonomic advice reduce the prevalence and severity of low back pain and pelvic girdle pain in pregnancy? A randomized controlled trial. Physical Therapy, 92, 781-790. doi:10.2522/ptj.20110119

[12] Morkved, S., Salvesen, K.A., Schei, B., Lydersen, S. and Bo, K. (2007) Does group training during pregnancy prevent lumbopelvic pain? A randomized clinical trial. Acta Obstetricia et Gynecologica Scandinavica, 86, 276-282. doi:10.1080/00016340601089651

[13] Gjestland, K., Bo, K., Owe, K.M. and Eberhard-Gran, M. (2012) Do pregnant women follow exercise guidelines? Prevalence data among 3482 women, and prediction of low-back pain, pelvic girdle pain and depression. British Journal of Sports Medicine, 47, 515-520.

[14] Mogren, I.M. (2005) Previous physical activity decreases the risk of low back pain and pelvic pain during pregnancy. Scandinavian Journal of Public Health, 33, 300306.

[15] Juhl, M., Andersen, P.K., Olsen, J. and Andersen, A.M. (2005) Psychosocial and physical work environment, and risk of pelvic pain in pregnancy. A study within the Danish national birth cohort. Journal of Epidemiology \& Community Health, 59, 580-585. doi:10.1136/jech.2004.029520

[16] Haakstad, L.A., Gundersen, I. and Bo, K. (2010) Selfreporting compared to motion monitor in the measurement of physical activity during pregnancy. Acta Obstetricia et Gynecologica Scandinavica, 89, 749-756. doi:10.3109/00016349.2010.484482

[17] Voldner, N., Froslie, K.F., Bo, K., Haakstad, L., Hoff, C., 
Godang, K., Bollerslev, J. and Henriksen, T. (2008) Modifiable determinants of fetal macrosomia: Role of lifestyle-related factors. Acta Obstetricia et Gynecologica Scandinavica, 87, 423-429. doi:10.1080/00016340801989825

[18] Voldner, N., Froslie, K.F., Haakstad, L.A., Bo, K. and Henriksen, T. (2009) Birth complications, overweight, and physical inactivity. Acta Obstetricia et Gynecologica Scandinavica, 88, 550-555. doi: $10.1080 / 00016340902818162$

[19] Caspersen, C.J., Powell, K.E. and Christenson, G.M. (1985) Physical activity, exercise, and physical fitness: definitions and distinctions for health-related research. Public Health Reports, 100, 126-131.

[20] Haakstad, L.A., Voldner, N., Henriksen, T. and Bo, K. (2007) Physical activity level and weight gain in a cohort of pregnant Norwegian women. Acta Obstetricia et Gynecologica Scandinavica, 86, 559-564. doi:10.1080/00016340601185301

[21] Mousavi, S.J., Parnianpour, M. and Vleeming, A. (2007) Pregnancy related pelvic girdle pain and low back pain in an Iranian population. Spine, 32, 100-104. doi:10.1097/01.brs.0000254123.26649.6e

[22] Bo, K. and Backe-Hansen, K.L. (2007) Do elite athletes experience low back, pelvic girdle and pelvic floor complaints during and after pregnancy? Scandinavian Journal of Medicine \& Science in Sports, 17, 480-487. doi:10.1111/j.1600-0838.2006.00599.x

[23] Robinson, H.S., Eskild, A., Heiberg, E. and EberhardGran, M. (2006) Pelvic girdle pain in pregnancy: The impact on function. Acta Obstetricia et Gynecologica Scandinavica, 85, 160-164. doi:10.1080/00016340500410024

[24] Albert, H.B., Godskesen, M. and Westergaard, J.G. (2002) Incidence of four syndromes of pregnancy-related pelvic joint pain. Spine, 27, 2831-2834. doi:10.1097/00007632-200212150-00020

[25] Stones, R.W. and Vits, K. (2005) Pelvic girdle pain in pregnancy. British Medical Journal, 331, 249-250. doi:10.1136/bmj.331.7511.249

[26] Cook, C., Massa, L., Harm-Ernandes, I., Segneri, R., Adcock, J., Kennedy, C. and Figuers, C. (2007) Interrater reliability and diagnostic accuracy of pelvic girdle pain classification. Journal of Manipulative and Physiological Therapeutics, 30, 252-258.

\section{doi:10.1016/j.jmpt.2007.03.008}

[27] Endresen, E.H. (1995) Pelvic pain and low back pain in pregnant women-An epidemiological study. Scandinavian Journal of Rheumatology, 24, 135-141. doi:10.3109/03009749509099301

[28] Gutke, A., Ostgaard, H.C. and Oberg, B. (2006) Pelvic girdle pain and lumbar pain in pregnancy: A cohort study of the consequences in terms of health and functioning. Spine, 31, E149-E155. doi:10.1097/01.brs.0000201259.63363.e1

[29] Larsen, E.C., Wilken-Jensen, C., Hansen, A., Jensen, D.V., Johansen, S., Minck, H., Wormslev, M., Davidsen, M. and Hansen, T.M. (1999) Symptom-giving pelvic girdle relaxation in pregnancy. I: Prevalence and risk factors. Acta Obstetricia et Gynecologica Scandinavica, 78, 105110. doi:10.1080/j.1600-0412.1999.780206.x

[30] Hansen, A., Jensen, D.V., Wormslev, M., Minck, H., Johansen, S., Larsen, E.C., Wilken-Jensen, C., Davidsen, M. and Hansen, T.M. (1999) Symptom-giving pelvic girdle relaxation in pregnancy. II: Symptoms and clinical signs. Acta Obstetricia et Gynecologica Scandinavica, 78, 111-115. doi:10.1080/j.1600-0412.1999.780207.x

[31] Albert, H.B., Godskesen, M., Korsholm, L. and Westergaard, J.G. (2006) Risk factors in developing pregnancyrelated pelvic girdle pain. Acta Obstetricia et Gynecologica Scandinavica, 85, 539-544. doi:10.1080/00016340600578415

[32] Ostergard, T., Jessen, N., Schmitz, O. and Mandarino, L.J. (2007) The effect of exercise, training, and inactivity on insulin sensitivity in diabetics and their relatives: What is new? Applied Physiology, Nutrition, and Metabolism, 32, 541-548. doi:10.1139/H07-031

[33] Agardh, E.E., Sidorchuk, A., Hallqvist, J., Ljung, R., Peterson, S., Moradi, T. and Allebeck, P. (2011) Burden of type 2 diabetes attributed to lower educational levels in Sweden. Population Health Metrics, 9, 60. doi:10.1186/1478-7954-9-60

[34] Adams, S.A., Matthews, C.E., Ebbeling, C.B., Moore, C.G., Cunningham, J.E., Fulton, J. and Hebert, J.R. (2005) The effect of social desirability and social approval on self-reports of physical activity. American Journal of Epidemiology, 161, 389-398. doi:10.1093/aje/kwi054 